\title{
A rare case of heterophagus twinning
}

\author{
*Y G T Priyawansha ${ }^{1}$, K D Munasinghe ${ }^{1}$, N Manike ${ }^{2}$
}

Sri Lanka Journal of Child Health, 2018; 47: 279-281

DOI: http://dx.doi.org/10.4038/sljch.v47i3.8555

(Key words: Heterophagus twinning, teratoma, tripedus, meningomyelocoele)

\section{Introduction}

The accessory limb or heterophagus twinning is a rare anomaly ${ }^{1-4}$. There are only a few recorded cases worldwide ${ }^{2,4}$. Often they accompany spina bifida or other anomalies of spinal structures ${ }^{2,3}$. Hypothetical theories have been described, including a defect in the early genesis of limbs associated with a neural tube defect, a consequence of a parasitic twin and the presence of a teratoma ${ }^{1,2,3,5}$. We report a child delivered with a well-developed skeletal component with no muscular component arising from the spine.

\section{Case report}

A 26 year old mother was admitted to Teaching Hospital, Kandy with spontaneous rupture of membranes at 36 weeks of gestation in her second pregnancy. Up to the current gestation, her antenatal period was uneventful. She has a healthy living child. Dribbling was recorded for 5 hours and the obstetric team decided to let her proceed with normal labour. The mother and the baby were regularly monitored and at delivery the presentation was a foot. Due to obstructed labour, the obstetric team decided to deliver the baby by lower segment caesarean section (LSCS). After delivery, his condition was well. At birth, the following problems were identified. He was small for gestational age, had a large abnormal extension which resembled a lower limb with joint, fingers and an inside bone, had a meningomyelocoele, and had bilateral talipes equinovarus. There were bilateral pre-auricular tags and an umbilical hernia (Figure 1). He was well with normal respiratory and cardiovascular parameters. His haematology was normal with negative blood culture. Ultrasound scans of brain and kidneys were normal.

${ }^{1}$ Registrar in Paediatrics, ${ }^{2}$ Consultant
Neonatologist, Neonatology Unit, $\quad$ Teaching
Hospital, Kandy
${ }^{*}$ Correspondence: thusharapriyawansha@gmail.com

(Received on 23 January 2017: Accepted after revision on 17 March 2017)

The authors declare that there are no conflicts of interest

Personal funding was used for the project.

Open Access Article published under the Creative

Commons Attribution CC-BY (C) (i)

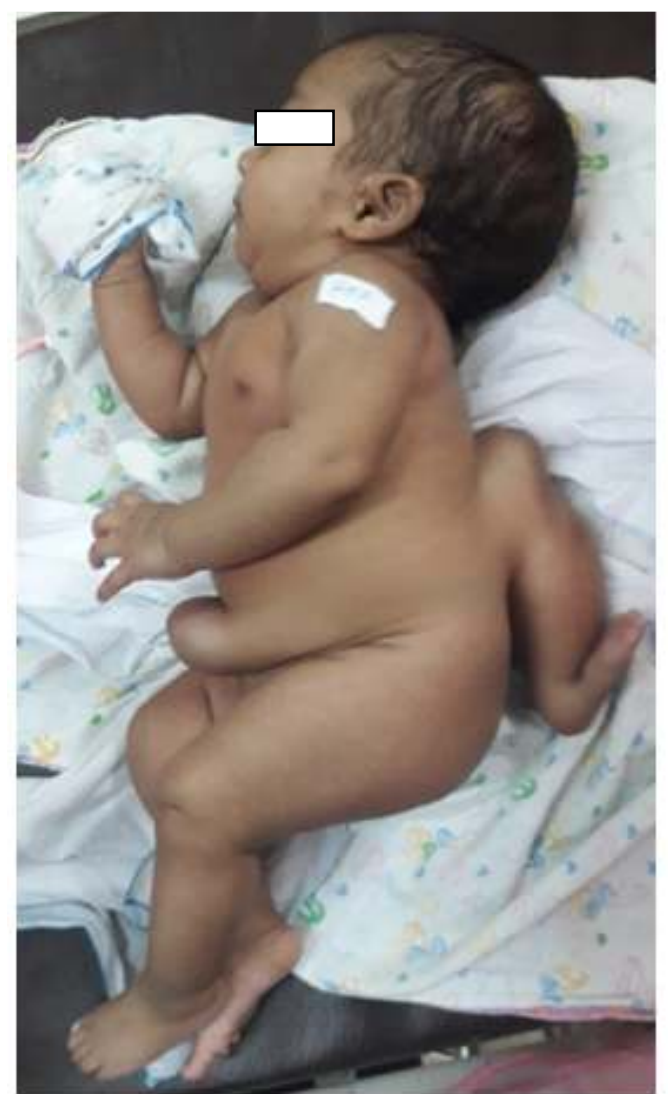

Figure 1: Baby with umbilical hernia and abnormal extension resembling lower limb

*Permission given by parents to publish
photograph

Hip scan revealed physiological immaturity of both hips. Magnetic resonance imaging (MRI) was done and the findings were: open spinal dysraphism of lower thoracic and upper lumbar vertebrae, meningomyelocoele with dural sac at thoracolumbar junction with protrusion of neural tissue, central canal dilated from cervico-medullary junction to distal end of the cord tethering to meningomyelocoele, an accessory limb attached to the meningomyelocoele sac and consisting of a long bone which could be the femur and a rudimentary foot; this limb was composed of a lipomatous mass covered by skin, with no muscle being visualised; there was no Chiari malformation and ventricles were normal with no hydrocephalus, with other brain findings being compatible with age (Figures 2 and 3). The ultrasound and CT scan findings were compatible with the MRI findings. 


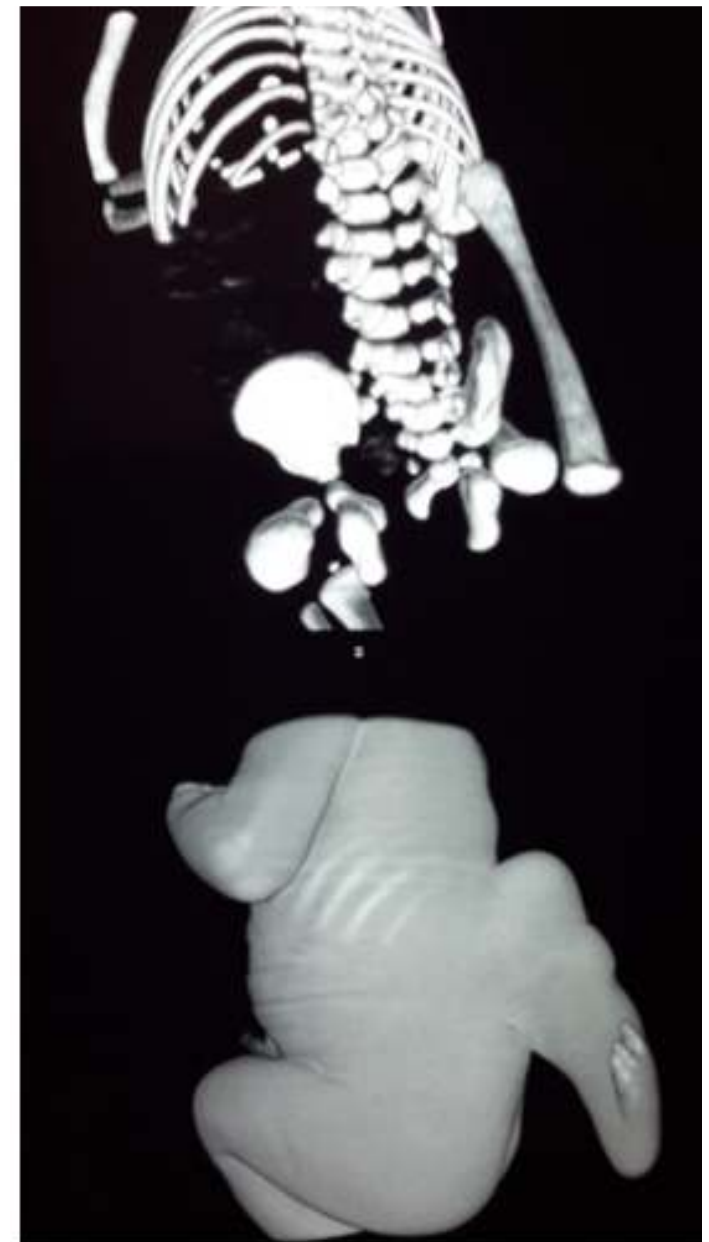

Figure 2: $A 3$ dimensional projection by magnetic resonance imaging

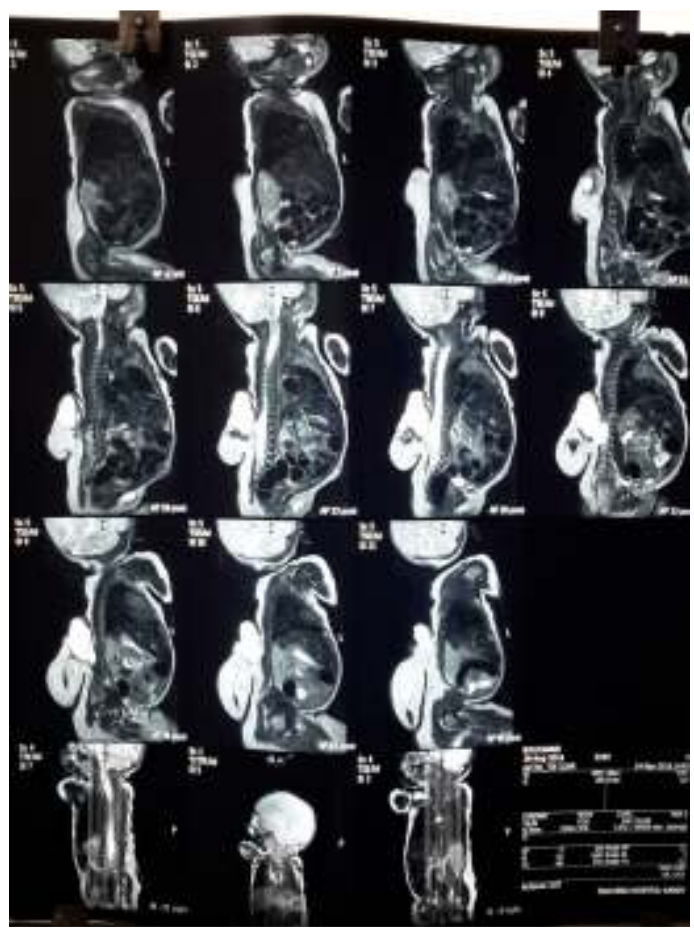

Figure 3: Magnetic resonance imaging of baby
On electromyography (EMG) there were no detectable functional motor units in this accessory limb. The findings of the EMG were normal in both lower limbs.

He underwent neurosurgical intervention on the $22^{\text {nd }}$ day of life and the immediate post-surgical period was uneventful. However, during successive days he had CSF leak and lower limb weakness was noted. On post-surgical day 8 , baby passed away possibly due to secondary infection by a virulent organism which did not grow in culture. Histopathology of the resected limb revealed that the anatomy of the accessory limb was normal with appropriate histology and no abnormal tissues components were seen with no neurovascular bundle being noticed.

\section{Discussion}

At present, there are only a few cases reported with varying degree of defect and associations ${ }^{1-5}$. There is no validated evidence of categorisation or causation including prognostication of this rare entity of anomaly ${ }^{1-3}$. Different nomenclatures are used. Some of them are: Heterotopic redundancy, aborted twinning, teratoma, tripedus, disorganisation like syndrome, heterophagus twinning, spinal hamartoma, mature teratoma, dorsal accessory limb, midline dorsal appendages, poor parasitic twin etc. ${ }^{1-5}$. One theory describes it occurring as a result of spinal dysraphism ${ }^{1,5}$. However, according to the latest hypothesis it follows the primary and secondary neural tube defect leading to spina bifida ${ }^{1,2}$. As a sequence, primary neural tube defect leads to spina bifida. The secondary neural tube defect leads to over secretion of neural tube fluid which then differentiate to lipomatous, cartilaginous, skeletal, muscular and neural structure developing an accessory limb $b^{1,2}$. Some authors find that heterophagus is due to the development of an asymmetrical twin ${ }^{2}$. One twin monopolizes the placental blood supply at the expense of other twin. Consequently, there is ischaemic atrophy of the latter. The remaining part of this developmental anomaly grows as a parasite. In some literature it is accepted that the theory behind this phenomenon is fusion hypothesis in embryogenesis ${ }^{2}$.

In this case, the limb was attached at the thoracolumbar region with full phenotypic lower limb and the histology excludes a teratoma. As the spine is mesodermal in origin there can be several structures of mesodermal origin. It supports the presence of spina bifida and meningomyelocoele of the same origin. 


\section{References}

1. Murphy RF, Cohen BH, Muhlbauer MS, Eubanks JW, Sawyer JR, Moisan A, et al. An accessory limb with lipomyelomeningocoele in a male. Pediatric Surgery International 2013; 29:749-52. https://doi.org/10.1007/s00383-013-32699

PMid: 23392915

2. Solak A, Ergun S, Polat I, Sahin N, Genc B. A rare form of heterophagus twinning: Three-armed infant with spinal dysraphism. Hindawi Publishing Corporation, Case Reports in Paediatrics 2012 (2012): Article ID 831649.

3. Kun-Bo P, Yeon-Mee K, Ji-Yong P, MiLim C, Yu-Jin J, So-Hyun N. An accessory limb with an imperforate anus. Annals of Surgical Treatment and Research 2014; 87(4): 213-6.

https://doi.org/10.4174/astr.2014.87.4.213

PMid: 25317418 PMCid: PMC4196430
4. Akyol D, Baltaci V, Kozinoglu H, Yuksel $\mathrm{K}$, Kis S, Clcek N, et al. Accessory limb attached to the back. Turkish Journal of Medical Sciences 1999; 29:199-201.

5. Krishna A, Lal P. Accessory limb associated with spina bifida: A second look. Pediatric Surgery International 1999: 15: $248-50$

https://doi.org/10.1007/s003830050568

PMid: 10370036 